Note

\section{Depside from an Isolated Lichen Mycobiont}

\author{
Nobuo Hamada and Tamio Ueno* \\ Laboratory of Applied Botany, and *Pesticide \\ Research Institute, Faculty of Agriculture, \\ Kyoto University, Kyoto 606, Japan
}

Received December 8, 1986

There have been three reports suggesting the production of lichen substances, especially depsides and depsidones, by a mycobiont without the co-operation of the algal partner. Komiya and Shibata ${ }^{1)}$ detected a small amount of salazinic acid in the mycobiont isolated from Ramalina crassa. Ejiri and Shibata ${ }^{2)}$ detected a small amount of squamatic acid in the mycobiont isolated from Cladonia crispata. Culberson and Ahmadjian ${ }^{3)}$ succeeded in recombining the $C$. cristatella mycobiont with phycobionts isolated from 13 species of lichens, and found that all the recombined cultures produced barbatic acid, which is the characteristic product of $C$. cristatella. This suggests that the mycobionts could form lichen substances without algal symbionts.

These results, however, do not rule out the participation of the algal partner in the production of lichen substances. In order to investigate the possibility that the phycobionts participate in the production of lichen substances, we examined the products of the cultivated mycobionts of two strains of $R$. siliquosa.

We found that 4-O-demethylbarbatic acid (Fig. 1-I), a $\beta$-orcinol depside, was produced in the cultivated mycobiont colonies from $R$. siliquosa in an amount equivalent to $0.6 \%$ of the dry weight in one strain and $0.1 \%$ in the other strain (see EXPERIMENTAL). On the other hand, as one of us reported previously, ${ }^{4,5)}$ the former strain (SA strain) produces $0.5 \sim 2.0 \%$ of salazinic acid (Fig. 1-II) as dry weight under the lichenized conditions of the collection site and the latter (PA strain) $0.1 \sim 0.3 \%$ of protocetraric acid (Fig. 1-III) as dry weight, both of which could not be detected in the mycobiont cultures. These results show that the $\beta$-orcinol depsidone, protocetraric acid, may be produced from 4- $O$-demethylbarbatic acid by oxidation of the 9- and 9'-positions and coupling of the oxygen at the 2-position to the $5^{\prime}$ carbon, and that salazinic acid may be produced on further oxidation at the 8 '-position. This report suggests that the algal partner plays an additional role, oxidation, in the production of lichen substances by the mycobiont, although there is another possibility that the structure of the lichen substances differs with the culture conditions.

\section{EXPERIMENTAL}

Mass spectral data were obtained with a Hitachi Model M-80 A mass spectrometer combined with a M-003 data processing system. NMR spectra were recorded on a JOEL FX-90Q spectrometer. Preparative HPLC was performed with a Hitachi 655 liquid chromatograph equipped with a UV-detector.

Identification of lichen substances and mycobiont products. Thalli of the SA strain of $R$. siliquosa with apothecia were collected in Kushimoto-cho, Wakayama Prefecture, Japan $\left(33^{\circ} \mathrm{N}\right)$, in January, 1985, and those of the PA strain on Kinkazan Island, Miyagi Prefecture, Japan $\left(39^{\circ} \mathrm{N}\right)$, in October, 1985 . In all thalli of the SA strain examined, salazinic acid, and in all thalli of the PA strain examined, protocetraric acid was detected by the method reported previously ${ }^{5}$ ); TLC (Kieselgel $\mathrm{GF}_{254}, 0.25 \mathrm{~mm}$ thickness), benzene-dioxane-acetic acid (90:25:4), $R f$ salazinic acid-protocetraric acid-4- $O$-demethylbarbatic acid (internal standard) 22:10:60, and hexane-ethyl ether-formic acid $(5: 4: 1), 18: 28: 64$.

The mycobionts of each strain were obtained from spores discharged from 50 apothecia collected from 50 thalli, and were cultured for 10 months in 200 test tubes containing a modified malt-yeast extract medium (malt extract $10 \mathrm{~g}$, yeast extrat $4 \mathrm{~g}$, agar $15 \mathrm{~g}$, water $11, \mathrm{pH} 7.0$ ), at $15^{\circ} \mathrm{C}$ in the dark. The mycelia, $10.5 \mathrm{~g}$, in dry weight,<smiles>Cc1cc(O)c(C)c(O)c1C(=O)Oc1cc(C)c(C(=O)O)c(O)c1C</smiles><smiles>Cc1cc(O)c(C=O)c2c1C(=O)Oc1c(CO)c(O)c3c(c1OC2O)C(=O)OC3O</smiles>
[II]<smiles>Cc1cc(O)c(C)c2c1C(=O)Oc1c(CO)c(O)c(C(=O)O)c(C)c1O2</smiles>

FIG. 1.

(I) 4-O-Demethylbarbatic acid.

(II) Salazinic acid.

(III) Protocetraric acid. 
from the SA strain and $8.3 \mathrm{~g}$ from the PA strain, were harvested, frozen and then extracted with cold acetone, and the extracts were examined by TLC on Kieselgel $\mathrm{GF}_{254}{ }^{6)}$ One depside was detected in the mycelia of both strains cultured for 6 and 10 months, but neither salazinic acid nor protocetraric acid was detected. The whole extract from each strain was subjected to column chromatography (Kieselgel G 60) with elution with hexane-ethyl ether-formic acid $(5: 4: 1)$ to obtain the depside. Both elutes were concentrated to dryness and then washed with chloroform to afford $c a .60 \mathrm{mg}$ of a solid material for the SA strain, and ca. $9 \mathrm{mg}$ for the PA strain. These materials were purified by HPLC; water-methanol-acetic acid $(20: 80: 2), t_{R} 5.2 \mathrm{~min}$ at $1.0 \mathrm{ml} / \mathrm{min}\left(80 \mathrm{~kg} / \mathrm{cm}^{2}\right)$ on a $15 \mathrm{~cm} \times 4.5 \mathrm{~mm}$ Zorbax ODS column (Dupont Instr.). The purified substance from the SA strain was identified as 4$O$-demethylbarbatic acid from MS, ${ }^{1} \mathrm{H}-\mathrm{NMR}$ and ${ }^{13} \mathrm{C}$ NMR data, and that from the PA strain was also identified as 4-O-demethylbarbatic acid from MS and ${ }^{1} \mathrm{H}-\mathrm{NMR}$ data. The same substance was detected in the mycobionts of both strains collected at other sites; Takuma-cho, Kagawa Prefecture $\left(34^{\circ} \mathrm{N}\right)$ (SA strain), and Itoh-city, Shizuoka Prefecture $\left(34^{\circ} \mathrm{N}\right)$ (PA strain).

\section{Spectral data for the isolated depside}

4-O-Demethylbarbatic acid $=4-\left(2^{\prime}, 4^{\prime}-\right.$ dihydroxy-3' ${ }^{\prime}, 6^{\prime}-$ dimethylbenzoyloxy)-2-hydroxy-3,6-dimethyl-benzoic acid. MS (In-beam EI, $70 \mathrm{eV}): \mathrm{m} / z 346\left(\mathrm{M}^{+}, 1.3 \%\right), 302(0.6 \%)$, $182(39.9 \%), 166(9.2 \%), 165(93.1 \%), 164(75.7 \%), 139$ $(6.5 \%), 138(67.4 \%), 137(40.4 \%), 136(100 \%), 123$ $(27.7 \%), 109(12.7 \%), 108(17.1 \%), 107(22.0 \%), 91$ $(14.9 \%), 83(14.0 \%), 79(22.1 \%), 77(18.7 \%), 55(12.1 \%)$, $53(19.5 \%), 43(12.8 \%)$ and $41(12.7 \%)^{7}$. ${ }^{1}$ H-NMR $\left(89.55 \mathrm{MHz}, \mathrm{CD}_{3} \mathrm{OD}\right): \delta 7.01(1 \mathrm{H}, \mathrm{s}), 6.85(1 \mathrm{H}, \mathrm{s}), 3.10$ $\left(3 \mathrm{H} \times 2\right.$, each s), $2.56(3 \mathrm{H}, \mathrm{s})$ and $2.54(3 \mathrm{H}, \mathrm{s}) .{ }^{13} \mathrm{C}-\mathrm{NMR}$ $\left(22.5 \mathrm{MHz}\right.$, DMSO- $\left.d_{6}\right): \delta 172.5,169.4,162.6,162.0,160.6$, $150.6,138.9,138.8,114.7,114.0,113.4,110.9,108.5,103.6$, 23.4, 22.7, 9.1 and 7.9 (each one carbon atom). ${ }^{8)}$

Acknowledgments. The authors wish to express their deepest appreciation to Professors A. Takimoto and $\mathrm{H}$. Fukami, Faculty of Agriculture, Kyoto University, for the critical reading of the manuscript and invaluable suggestions. The authors also wish to thank Dr. R. Nishida, Faculty of Agriculture, Kyoto University, and Dr. T. Nakashima, Forestry and Forest Products Research Institute, Tsukuba, for their experimental support in the NMR and MS measurements.

\section{REFERENCES}

1) T. Komiya and S. Shibata, Chem. Pharm. Bull. (Japan), 17, 1305 (1969).

2) H. Ejiri and S. Shibata, phytochemistry, 13, 2871 (1974).

3) C. F. Culberson and V. Ahmadjian, Mycologia, 72, 90 (1980).

4) N. Hamada, Can. J. Bot., 60, 379 (1982).

5) N. Hamada, J. Jap. Bot., 60, 40 (1985).

6) C. F. Culberson, J. Chromatog., 46, 85 (1970).

7) S. Huneck, G. Follmann and J. Santesson, Z. Naturforsch., 23b, 856 (1968).

8) E. G. Sundfolm and S. Huneck, Chemica Scripta, 18, 233 (1981). 